\title{
O DIA "D” DA EDUCAÇÃO MINEIRA: JOGOS ESTRATÉGICOS DE PODER-SABER
}

\author{
Marcio Moterani Swerts ${ }^{1}$ \\ Marcelo Vicentin ${ }^{2}$ \\ Eloisa Rosotti Navarro ${ }^{3}$ \\ Rogério de Melo Grillo
}

\begin{abstract}
Resumo:
O presente artigo é um recorte de uma pesquisa que teve como objetivo problematizar, suspeitar e analisar criticamente o discurso presente nos documentos específicos do Dia "D" da Educação de Minas Gerais, visando depreender como se dão os jogos de estratégias de poder-saber, principalmente, em torno da expressão Dia "D". Para tanto, tomamos como referencial metodológico as propostas de análise de discurso foucaultiana sobre o principal documento oficial concernente à organização do Dia "D": o Guia para organização do Dia " $D$ " ("Guia de orientação para a reorganização e implementação do Plano de Intervenção Pedagógica - 2010/2011"). Destarte, apresentaremos nesse artigo uma analítica em relação ao poder-saber, ao poder político, ao governamento e às estratégias de governamentalidade que norteiam o discurso do Dia "D" da Educação Mineira. De resto, as nossas análises evidenciam que o Dia "D", além de uma operação de jogada política, possui uma função governamental-pastoral, uma vez que tem como escopo a construção de um sujeito de consciência guiado aos resultados, aos melhores índices em avaliações em larga escala (IDEB, PROALFA, SIMAVE).
\end{abstract}

Palavras-chave: Dia “D”. Governamentalidade. Avaliação em Larga Escala. Educação.

\section{THE "D-DAY" OF MINEIRA EDUCATION: STRATEGIC GAMES OF POWER- KNOWLEDGE}

\begin{abstract}
:
This article is an excerpt from a research that aimed to problematize, suspect and critically analyze the discourse present in the specific documents of the "D" Day of Education in Minas Gerais, aiming to understand how the power strategy games take place. to know, mainly, around the expression "D" Day. To this end, we take as a methodological reference the proposals for the analysis of Foucault's discourse on the main official document concerning the organization of " $\mathrm{D}$ " Day: the Guide for the organization of "D" Day ("Guide for the reorganization and implementation of the Pedagogical Intervention - 2010/2011"). Thus, we will present in this article an analysis in relation to the power-to-know, the political power, the government and the governmentality strategies that guide the discourse of the "D" Day of Minas Gerais Education. In addition, our analyzes show that
\end{abstract}

1 Possui doutorado em Educação pela Universidade de São Francisco (2016). Mestrado em Mestrado em Educação pela Universidade Vale do Rio Verde de Três Corações (2005). Tem experiência na área de Educação, com ênfase em Educação, atuando principalmente nos seguintes temas: interdisciplinaridade, psicologia, portador de deficiência, motivação e motivos humanos. E-mail: marcioswerts@ hotmail.com.

2 Pós-Doutorando em Educação (2018), Doutor em Educação (2018) e Mestre em Educação (2013) pela Universidade São Francisco (USF); Especialista em Mídias na Educação (2012) pela Universidade Federal de Pernambuco (UFPE); Bacharel em Cinema (1995) pela Faculdade Armando Alvares Penteado (FAAP), Licenciado em Língua Portuguesa pelas Faculdades Integradas Teresa Martin (2003). E-mail: marcelovicentin@yahoo.com.br.

3 Doutoranda em Educação pela Universidade Federal de São Carlos (UFSCAR), na linha de pesquisa em Educação Matemática. Mestre em Educação em Ciência e em Matemática pela Universidade Federal do Paraná (UFPR), na área de Tecnologia e Educação Matemática (2015). Licenciada em Matemática pela Universidade Estadual de Maringá - UEM (2012). E-mail: eloisa-rn@ hotmail.com.

4 Doutor em Educação Física pela Universidade Estadual de Campinas - UNICAMP (2014). Possui Mestrado em Educação pela Universidade São Francisco (2012), campus Itatiba/SP. Licenciatura Plena em Educação Física (2005) e Especialização em Educação Física Escolar (2007) pelo Centro Universitário Claretiano de Batatais/SP. Graduação em Pedagogia pela FAFIBE (MG). E-mail: rogerio.grillo@ hotmail.com. 
D-Day, in addition to a political move operation, has a governmental-pastoral function, since it aims to build a subject of conscience guided to results, to the best rates in large-scale evaluations (IDEB, PROALFA, SIMAVE).

Keywords: D-Day. Governmentality. Large Scale Evaluation. Education.

\section{INTRODUÇÃO}

A política educacional proposta pela Secretaria de Educação do Estado de Minas Gerais, a partir dos anos 2000, foi pautada em programas como o Programa de Avaliação da Rede Pública de Educação Básica (PROEB) e o Programa de Avaliação da Alfabetização (PROALFA). Estes programas passaram a conduzir a produção de indicadores para intervenções sobre setores e segmentos educacionais objetivando erradicar possíveis problemas presentes na rede escolar. Juntos visam, de maneira integrada, proporcionar resultados confiáveis por meio de estatísticas para a organização das políticas públicas de intervenção direta em todos os segmentos, mais intensamente sobre a sala de aula.

A discussão dos resultados, das estatísticas, das classificações, do relatório final é promovida num evento que suspende todas as atividades escolares letivas nas escolas públicas de Minas Gerais, para discutir e produzir decisões estratégicas para combater e corrigir "erros" de caminhada que estariam atrapalhando a construção de resultados de excelência para o processo de ensino. Destarte, propende-se fortemente aos alunos que apresentam "baixo desempenho" nas estatísticas constantes no(s) relatório(s) da avaliação sistêmica externa.

O evento, estrategicamente, é nomeado de O Dia "D” nas escolas. Vale aludir que o primeiro dia "D” (naquele momento era conhecido também como reunião do PIP) ocorreu no ano de 2007 e, naquela ocasião, foram analisados os resultados das avaliações de 2006. O que ocorreu, de fato, no ano de 2007, foi um evento que funcionou mais como um "teste", uma "preparação" para o "ataque bélico" que viria anos depois.

Desse modo, em 08 de dezembro de 2010, data que registra oficialmente o dia “D” (apesar de ser o segundo evento), tem-se, portanto, de maneira documental (formulação do guia de orientação) e propagandística, o "ataque bélico". Ataque este epitetado como o dia em que: "Toda a escola pode fazer a diferença" (slogan do dia "D").

Com isso, o presente artigo tem como objetivo "problematizar, suspeitar e analisar criticamente o discurso presente nos documentos específicos do Dia ' $D$ ', com vistas a

\begin{tabular}{|l|l|l|l|l|}
\hline Gevista Dialectus & Ano 9 & n. 19 & Agosto-Dezembro 2020 & p. 256-276 \\
\hline
\end{tabular}


compreender como se dão os jogos de estratégias de poder-saber, sobretudo, em torno da expressão Dia 'D'.”

Para tanto, destacamos que esse artigo foi organizado a partir de uma abordagem qualitativa, a qual se assume como referência/inspiração as propostas de análise de discurso foucaultiana diante do principal documento oficial atinente à organização do Dia "D": o Guia para organização do Dia "D” (“Guia de orientação para a reorganização e implementação do Plano de Intervenção Pedagógica - 2010/2011”). Concatenado a esse documento, analisaremos, de modo complementar, os discursos referentes ao Dia "D”, em especial, presentes no documento: "Guia de revisão e reorganização do Plano de Intervenção Pedagógica - 2013” (este é uma continuidade do documento produzido em 2010/2011).

Entendemos que cada escrita, todas elas e muitas delas são narrativas que nos levam muito além da simples fala, ou ainda, do simples escrito e, até mesmo, do simples enunciado. Elas sempre dizem mais. Ora, os discursos políticos e educacionais se constituem por uma rede de fios discursivos, que se entrecruzam, emaranham, interpenetram e transversalizam, de forma que a tessitura se torna impossível de desintrincar e/ou desfiar ao se pinçar um só fio, no intuito de que ele se separe da trama do tecido. Subsequentemente, remete a outros discursos, quer sejam o curricular, o pedagógico, o ideológico e/ou o científico. Nessa rede, todos sofrem movimentos para se constituírem num outro tecido, que embora desgastado, ainda é um "novo".

Dessarte, é nesse continum constante, que a cada ano, a cada momento, e, mormente, em cada ato e/ou atitude dos sujeitos que permeiam a Educação em Minas Gerais, desencadeiam-se construções discursivas de assujeitamento, de manobras políticas sobre as instituições escolares, estatísticas para as políticas sociais, os financiamentos internacionais, os investimentos por controladores externos.

Em vista disso, organizamos o presente artigo em três seções. Na primeira, essencialmente, nós trabalharemos uma analítica em relação ao poder, ao poder político, ao governamento e às estratégias de governamentalidade, tomando como referência os estudos de Michel Foucault, Jorge Ramos do Ó e Silvio Gallo. Na segunda, apresentaremos a "governamentalidade como ferramenta", objetivando utilizar das ideias de Foucault para problematizar e colocar em suspeita o Dia " $D$ ” da Educação Mineira. Na terceira, apresentaremos os documentos, bem como, a problematização e análise realizada discursivamente sobre os mesmos. De resto, ousaremos indicar nossas problematizações,

\begin{tabular}{|l|l|l|l|l|}
\hline Gevista Dialectus & Ano 9 & n. 19 & Agosto-Dezembro 2020 & p. 256-276 \\
\hline
\end{tabular}


análises e críticas em “Considerações...”. Precipuamente, constituirão fundamento e suporte na problematização, na sustentação teórica e na análise, os estudos de Michel Foucault, Jorge Ramos do Ó, Sylvio Gadelha e Silvio Gallo.

\section{GOVERNAMENTALIDADE: PROCEDIMENTOS E TECNOLOGIAS}

Com a finalidade de analisar e problematizar o que denominou de dispositivos de segurança, Michel Foucault estudou criticamente as relações de poder-saber e alguns comportamentos da população presentes na Antiguidade Greco-Romana e na Idade Média, o que lhe permitiu elaborar pertinentes problematizações acerca da questão relacionada ao governo das pessoas.

Este governo se estabelece a partir de uma "engrenagem", ou melhor, de uma relação entre população, segurança e território. Esse grande inventário foi apresentado em cursos $^{5}$ no Collège de France no final dos anos de 1970, intitulados Segurança, Território e População (1977-8) e Nascimento da Biopolítica (1978-9).

Nos supracitados cursos, Foucault, de maneira apriorística, delineou uma questão

ampla de uma arte de governar, apresentando o neologismo "governamentalidade". Por consequência, debateu a governamentalidade, entrementes, visando atrelá-la ao Liberalismo como crítica estratégica as formas de governar, isso em uma perspectiva de razão de Estado, em especial, da racionalidade do Estado em governamentalizar.

Segundo Gallo (2013), antes de arquitetar o conceito de governamentalidade, Michel Foucault preocupou-se em esclarecer a noção de população, explanando-a como o ponto articulador de um triângulo formado pela soberania, disciplina e gestão governamental, maquinaria pelo qual mecanismos precípuos são formados pelos dispositivos de segurança. Ademais, essa triangulação persiste regulando nossas vidas, pois os três movimentos (governo, população e economia política) constituem, a partir do século XVIII, uma base sólida que seguramente não foi desassociada hodiernamente.

Ramos do Ó (2007), por conseguinte, explica que este modelo biopolítico teve enorme aceleração após o século XVIII. Por isso, o Estado foi se afirmando a partir de formas

\footnotetext{
5 Os cursos ministrados por Foucault foram organizados e constituíram-se em livros por meio dos seus alunos e cursistas. São compilações de aula por aula e as citações presentes nesse trabalho poderão vir com o tratamento na primeira pessoa do singular, uma vez que é o próprio Foucault quem fala.

\begin{tabular}{|c|c|c|c|c|}
\hline Revista Alatectus & Ano 9 & n. 19 & Agosto - Dezembro 2020 & p. $256-276$ \\
\hline
\end{tabular}
}


de notação, coleção, representação, acumulação, quantificação, sistematização e transporte de informações sobre a população, retroalimentando-se, principalmente, dos contínuos processos de reconstrução do espaço e tempo social.

Em suma, foi após o século XV (e desde antes da Reforma), que eclodiu a arte de governar os homens, eclosão esta entendida em um duplo sentido. Primeiro, de um deslocamento de início em relação a seu foco religioso, isto é, de laicização, de expansão na sociedade civil rumo a esse tema da arte de governar os homens e das técnicas para fazê-la.

Num segundo sentido, a multiplicação dessa arte de governar ocorreu em domínios variados, tais como: modos de governar as crianças, como governar os pobres e os mendigos, como governar uma família ou uma casa, como governar os exércitos, como governar os diferentes territórios (as cidades, os Estados), como governar seu próprio corpo, como governar seu próprio espírito etc. (Foucault, 1990).

Essa ideia de "como governar", é uma das questões centrais do que se passou entre os séculos XV e XVI. De fato, esta questão, essa governamentalidade, correspondeu a uma multiplicação de todas as artes de governar (arte pedagógica, arte política, arte econômica), tal qual, de todas as instituições de governo, num sentido geral, que tinha a palavra governo nessa época.

\footnotetext{
Ao fundir o governar (gouverner) e a mentalidade (mentalité) no neologismo governamentalidade, Foucault enfatiza a interdependência entre o exercício do governamento (práticas) e as mentalidades que sustentam tais práticas. Em outras palavras, a governamentalidade pode ser descrita como o esforço de criar sujeitos governáveis através de várias técnicas desenvolvidas de controle, normalização e moldagem das condutas das pessoas (Fimyar, 2009, p. 38).
}

Podemos tomar como exemplo, o comportamento de um rei, de um príncipe, ou também, dos vassalos perante os tratados e documentos. Ora, todos estes comportamentos podem ser analisados como uma condição para se depreender o exercício do poder de um ou uns sobre o outro ou outros, constituindo, com isso, uma arte de governar.

Esta arte de governar (ou governamentalização), com o escopo de "criar sujeitos governáveis", faz uso de técnicas de controle (exame, vigilância, etc.), regras de condutas, normalização, dispositivos disciplinares, dentre outros, que se estendem a população, com vistas a produzir subjetividades. Em outras palavras, é um mote de estratégias colocadas, mas sem estrategistas.

\begin{tabular}{|l|l|l|l|l|}
\hline Qenista Dialectus & Ano 9 & n. 19 & Agosto-Dezembro 2020 & p. 256-276 \\
\hline
\end{tabular}


Sinteticamente, pode-se analisar que esse conjunto de técnicas, normas e regras, tem como fim associar todos os aspectos de nossas práticas cotidianas num todo coeso, que toda e qualquer experiência deve ser isolada, medida, analisada e, por fim, atrelada a certos domínios apropriados, seja de estudo teórico, seja em planos de intervenção política, etc.

Vale ressaltar que em tais domínios, as normas, as regras e as técnicas não são estáticas, pelo contrário, se ramificam dinamicamente. Essa ramificação propende a colonizar, a instaurar, a impor, nos mínimos detalhes, as práticas dos sujeitos, para que, com isso, nenhuma ação tida como importante delas escape.

Nessa perspectiva, a arte de governar se projeta a um movimento relativo à sujeição individual diante a realidade de uma prática social. No entanto, para que esta sujeição aconteça, é basilar existir mecanismos de poder (discursivos, disciplinares) que apelem para a "verdade" (regras de conduta que determinam as maneiras de pensar, de ver, de falar e de agir).

Ademais, esta arte está presente igualmente nos modos de agir e/ou nas ações de aconselhamento para amar, agradar e obedecer a Deus (poder pastoral). Seja na forma de lei verbal e não escrita, as pessoas se organizam em torno de uma maneira de ser, de estar e de agir no mundo, comportando-se devidamente como se espera delas.

É interessante analisar que o Estado governamentalizado tem como objeto a população e não mais o território. Dessa forma, emprega-se de um saber econômico que controla a sociedade por dispositivos de segurança e por intermédio de práticas de governamento e/ou da gestão governamental do Estado Moderno que tem na população seu objeto, na economia seu saber e nos dispositivos de segurança seus mecanismos básicos.

Gallo (2013, p. 222) esquematiza o Estado governamentalizado da seguinte maneira:

[...] partiria de um "Estado de justiça", passando por um "Estado administrativo", para enfim chegar a um "Estado de governo". Segundo ele [Foucault], a governamentalização do Estado apoiou-se em um tripé formado pelo "poder pastoral", isto é, a concepção do dirigente político como um pastor e a população como um rebanho, que a analítica foucaultiana mostra que não existia entre os gregos, mas vem de uma fonte hebraica, tendo vicejado no Ocidente com o cristianismo; por uma nova técnica diplomático-militar; e, por fim, pelo "Estado de polícia", compreendido como o Estado administrado.

É precisamente este Estado de Governo que tem precipuamente como finalidade a população, considerada uma categoria abstrata, sem carne ou sangue. Ora, para atingir seus

\begin{tabular}{|l|l|l|l|l|}
\hline Qonista 2 Dialectus & Ano 9 & n. 19 & Agosto - Dezembro 2020 & p. 256-276 \\
\hline
\end{tabular}


objetivos, este tipo de Estado, a partir de uma gestão dos interesses da população, utiliza-se da instrumentalização do saber econômico e do saber político. Em outras palavras, é uma sociedade controlada por dispositivos de segurança (polícia, leis e punições, panóptico ${ }^{6}$, sinóptico $^{7}$, etc.).

Nesse contexto, ser obedecido ou fazer-se obedecer compõe, laconicamente, uma arte de governar, seja o governo de pessoas, coisas, riquezas, seja no controle dos outros ou de si mesmo. E nas mais diversas épocas, nas mais diversas crises sociais e econômicas vivenciadas pelas sociedades, o problema do governamento sempre esteve (e ainda estará) presente mediante de questões territoriais, econômicas, populacionais, pela salvação dos homens e de suas almas, etc.

A governamentalidade, portanto, utiliza saberes concernentes à economia política que abarca relações contínuas entre a população, o território, a riqueza, constituindo-se em ciência, quer dizer, uma ciência de governar. Basicamente, se suplanta uma arte de governo, atingindo uma ciência política, como de soberania para técnicas de governo (razão do estado), ou uma soberania-disciplina-gestão governamental que tem na população seu desígnio principal. Sumariamente, uma forma de governo de Estado pelo qual um conjunto de coisas e de homens deve estar disposto corretamente e ser conduzido estrategicamente, por regras e normas de ordenação, regulação e controle (Gadelha, 2009).

Pode-se dizer a arte de governar engendra certas operações de poder-saber, tais como poder normalizador, que se configuraram, paulatinamente no percorrer da história, num

6 Panóptico (pan: tudo; optikós: visão): é um termo usado para designar uma elevada torre central (numa prisão) com um vigilante, com vistas a vigiar todas as celas, e, concomitantemente, controlar os movimentos dos presos, regular meticulosamente o tempo e igualmente distribuir os detentos no espaço. Segundo Foucault (2011, p. 169), o Panóptico "funciona como uma espécie de laboratório de poder. Graças a seus mecanismos de observação, ganha em eficácia e em capacidade de penetração no comportamento dos homens; um aumento de saber vem se implantar em todas as frentes do poder, descobrindo objetos que devem ser conhecidos em todas as superfícies onde este se exerça”. Em suma, foi desenvolvido a partir do princípio de que o poder devia ser visível e inverificável. De resto, vale dizer que esse dispositivo disciplinar foi idealizado por Jeremy Bentham em 1791, para a reorganização das prisões.

7 Sinóptico: (sin: instante; optikós: visão): é um termo que se refere a um determinado tipo de dispositivo de controle que não necessita de coerção, ou seja, ele seduz as pessoas à vigilância. Em outros termos, o ato da vigilância desloca os vigilantes de sua localidade, isto é, os transporta pelos meios de comunicação, como o ciberespaço. Atinente a essa categoria, temos as câmeras instaladas em diversos lugares (incluindo escolas). É preciso ressaltar que, na sociedade disciplinar, o observador está presente e em tempo real, visando observar e a vigiar os indivíduos. Em contrapartida, numa sociedade de controle, o sinóptico torna-se virtual e digital, visto que independe de qualquer tipo de confinamento territorial. Este termo foi aludido por Gilles Deleuze ao conceituar a sociedade de controle e desenvolvido, mormente, por Thomas Mathiesen no texto The viewer society: Michel Foucault's 'Panopticon' revisited (1997), e por Zygmunt Bauman no livro Globalização: As consequências humanas (1999).

\begin{tabular}{|l|c|c|c|c|}
\hline Q Povista Dialectus & Ano 9 & n. 19 & Agosto-Dezembro 2020 & p. 256-276 \\
\hline
\end{tabular}


conjunto de dispositivos ágeis, eficazes e móveis, com o propósito de controlar a população de diferentes maneiras (espaço, tempo, formas de agir, pensar, falar, ser).

Esta arte também institui critérios para o estabelecimento de uma verdade, a do Estado. Verdade esta produzida, sobretudo, pelo discurso científico, pelas dinâmicas políticas de governo e pelas práticas do governo de si. Verdade esta a qual estabelece que a liberdade do indivíduo é, portanto, uma condição para a sua sujeição. Em outros termos, o exercício da autoridade implica uma existência de um livre indivíduo de desejo, necessidades, escolhas, interesses, hobbies e direitos. Contudo, a sujeição deste indivíduo é uma condição para a sua liberdade. Porém, "agir livremente" requer do indivíduo que ele esteja moldado, resignado, esquadrinhado e norteado, conforme os princípios preestabelecidos pelo Estado, para que, assim, possa exercer com primor a sua "liberdade".

Como exemplo, podemos observar a escola. Nesta instituição há certas práticas disciplinares que evidenciam os processos de sujeição, segundo explanados no parágrafo supramencionado. Na escola defendem a figura de um aluno livre, com liberdade para agir, falar, produzir conhecimentos etc., mas, é uma liberdade regulada, quer dizer, cada subjetividade é ponto de passagem de preceitos e jogos de poder-saber. Por sua vez, o discurso pedagógico se volta para um tipo de aluno responsável, autônomo. Este, consecutivamente, tem por função essencial se adaptar a vida escolar. Em resumo, no final das contas, o aluno será responsabilizado pelo seu sucesso ou fracasso diante de avaliações internas ou externas, será punido por casos de indisciplina ou delinquência perante as leis da escola (prescritas ou veladas), será excluído por uma possível forma de ser, de agir e pensar.

Nesse contexto, por um lado as práticas de liberdade concatenam-se, consultamse, negociam-se, criam-se parcerias ou mesmo conferem poder umas as outras, intensificando modos de agenciamento, liberdade de escolhas dos indivíduos (consumidores, profissionais, famílias em geral, grupos e sociedades). Por outro lado, tais práticas produzem normas de conduta, modelos, formas de exames, condições, indicadores de desempenho, controles de qualidade, padrões práticos para monitorar, mensurar e calcular o desempenho das várias instituições do Estado.

Por fim, é possível compreender que a "arte de governar" é resultado da formação de um saber político que se preocupa, exclusivamente, com a noção de população e suas formas de regulação. Ora, a governamentalidade é, sumariamente, uma disposição, uma distribuição e uma organização das coisas, a qual há a existência de uma espécie de

\begin{tabular}{|l|l|l|l|l|}
\hline Gevista Qialectus & Ano 9 & n. 19 & Agosto-Dezembro 2020 & p. $256-276$ \\
\hline
\end{tabular}


articulação que faz com que o sujeito governe a si próprio e, consequentemente, governe os outros.

\section{A GOVERNAMENTALIDADE COMO FERRAMENTA DE ANÁLISE}

A governamentalidade pode ser compreendida como o governar e o controlar a vida em uma multiplicidade qualquer, à condição de que a multiplicidade seja numerosa, ou seja, uma população, disposta num espaço aberto ou extenso.

Foucault, nos seus cursos, o arquitetou a governamentalidade como

[...] o conjunto constituído pelas instituições, os procedimentos, análises e reflexões, os cálculos e as táticas que permitem exercer essa forma bastante específica, embora muito complexa, de poder que tem por alvo principal a população, por principal forma de saber a economia política e por instrumento técnico essencial os dispositivos de segurança (FOUCAULT, 2008, p. 143-44).

Por intermédio desse viés e tomando a escola como exemplo, podemos analisar que a mesma é um território, um espaço, um lócus para o poder se fazer presente e a governamentalidade estar. Do conceito supracitado por Foucault, sublinhamos algumas palavras, como "conjunto", "procedimentos", "análises e reflexões", "cálculos e táticas", “discursividades”, sendo estas precípuas para compreender a prática da governamentalidade.

Tais palavras carregam a noção de como se governa as pessoas e/ou o grupo de pessoas, seus possíveis comportamentos públicos privados, em uma racionalidade que, conforme Gadelha (2009, p. 120) abrange "conjuntos de procedimentos, mecanismos, táticas, saberes, técnicas e instrumentos destinados a dirigir a conduta dos homens". Assim, a governamentalidade nos remete a elementos conceituais de sujeitos governáveis, normalização e condutas.

Desse modo, é possível analisar que as relações entre escola e sociedade não podem ser desatreladas, nem mesmo as relações interpessoais, visto que são transpostas e sustentadas pelo poder-saber. Nesse contexto, a governamentalidade como uma ferramenta de análise permite descrever, depreender, analisar, problematizar e esquematizar as formas de produção de discurso, as relações de poder-saber, as técnicas e dispositivos usados na arte de governar. Assim, é possível observar o ponto de mutação na arte de governar, ou seja, a

\begin{tabular}{|l|l|l|l|l|}
\hline Q Povista Dialectus & Ano 9 & n. 19 & Agosto-Dezembro 2020 & p. 256-276 \\
\hline
\end{tabular}


maneira como certos dispositivos, instrumentos e técnicas é aperfeiçoada, reorganizada e reestruturada.

Dessarte, compreender a governamentalidade como ferramenta, requer o seu uso na problematização de acontecimentos, relatos, formas de pensamento, em que são assumidos normativamente como verdade de Estado. Em específico, é problematizar, suspeitar e criticar, objetivando descortinar e desconstruir estas variadas práticas, elementos e meios que constituem esta aludida verdade de Estado.

Em síntese, não temos a intenção, no presente artigo, de produzir algo verdadeiro, num sentido de definitivo, absoluto, peremptório. Ora, pretendemos mostrar os jogos estratégicos de poder-saber, analisar o posicionamento das "peças" em jogo, depreender as micropráticas, os discursos velados, as verdades modestas e os estranhamentos advindos do Dia "D" da Educação Mineira.

Na próxima seção, faremos uso das ideias de Foucault, mormente, no que tange a governamentalidade, com o propósito de problematizar e colocar em suspeita o Dia "D" da Educação Mineira.

\section{DIA "D"8 DA EDUCAÇÃO MINEIRA: A PROPOSTA PARA A INVERVENÇÃO}

Analisando os dois documentos que compõem o corpus em questão: o "Guia de reorganização e implementação do plano de intervenção pedagógica 2010-2011" e o "Guia de revisão e reorganização do plano de intervenção pedagógica 2013”.

Defendemos que a análise de discurso, assumida neste artigo, visa à compreensão dos modos de (re)construção e produção de sentidos no documento aludido, isto é, analisar quais os discursos/enunciados que o Dia " $D$ " evocam. Nessa linha de pensamento, utilizaremos dos processos de desconstrução sob a égide foucaultiana que, de acordo com Mascia (2002, p. 40), objetiva

8 O D-Day (também conhecido como Operação Netuno, foi uma fase que encetou a conhecida Operação Overlord ou "suserano") é tido como o fato mais famoso da história militar. Foi a nona operação da Segunda Guerra Mundial. Na verdade, a invasão seria no dia 05/06/1944, no entanto, devido ao mau tempo, a operação foi adiada por 24 horas. O Dia D corroborou definitivamente para o enfraquecimento do exército nazista no eixo ocidental e findou na libertação da França. No eixo oriental, os soviéticos estavam rumo a Berlim no ano de 1944 e, em 1945, o general soviético Chuikov toma Berlim. Em 08 de maio de 1945, a Alemanha nazista se rende aos aliados. Em suma, a utilização do título "Dia D" refere-se como início de uma atividade ou mesmo de uma operação, em sua fase de planejamento, a qual leva em consideração que várias medidas devem ser tomadas antes e após o início dos combates, sendo que tais medidas devem ser organizadas em função de data e hora precisas da operação. Dessarte, o planejamento é estruturado marcando-se o Dia (D), Hora (H) e Minuto (M) do começo da ação (DAVIES, 2009).

\begin{tabular}{|l|c|c|c|c|}
\hline Gevista Dialectus & Ano 9 & n. 19 & Agosto-Dezembro 2020 & p. $256-276$ \\
\hline
\end{tabular}


[...] expor aquilo que o texto tenta esconder: os paradoxos, as contradições e as incoerências, pois a desconstrução não tem a finalidade de demonstrar o que o esquema argumentativo de um texto é falso ou errado; ela não disputa a verdade.

Ademais, não ousaremos proferir "o que é verdadeiro" ou "o que não é verdadeiro". Nossa proposta é articular, problematizar e suspeitar dos discursos presentes nesse "guia", para com isso, construir outros significados e sentidos sobre o Dia "D", em especial, fazendo uso da governamentalidade como ferramenta.

Ora, estamos buscando não uma verdade, mas nos interessa compreender o verdadeiro discurso nos meandros do documento referente ao Dia " $D$ " da Educação Mineira. Visamos descortinar, desvelar, desintrincar os jogos estratégicos de poder-saber presentes nesse documento. Cremos que assim é possível compreender como se dá esse jogo político, que é o Dia "D” da Educação Mineira.

Concebemos que ao trabalhar com o enunciado Dia "D" da educação em Minas Gerais, estaremos problematizando os jogos estratégicos de poder por seus efeitos de sentido. Cabe relembrar que o Dia "D" concerne à suspensão das atividades escolares para que sejam discutidos números oficiais, estatísticas, e, a partir das discussões, desenvolver proposições que possam reverter resultados de baixo rendimento presentes no(s) relatório(s) da avaliação sistêmica externa.

Do mesmo modo que o Dia D (Segunda Guerra Mundial) foi uma operação militar que abarcou um ataque em larga escala, mobilizando milhares de soldados e armamentos, sobre um alvo determinado em um único dia (podendo se estender para além dele), no caso de $M G$, o Dia " $D$ " na Educação não fugia a esta regra. Em outras palavras, havia um cronograma rígido e preestabelecido, tinha também um processo de mobilização dos professores (os mesmos são passiveis de punição caso se ausentem), existia todo um roteiro a ser seguido, com relatórios pós-Dia “D”, relatórios de intervenção pedagógica (PIP), metas a serem alcançadas, e, é claro, um guia norteador (documento analisado na presente pesquisa). Todo este plano, esta mobilização, a ser aplicada em um único dia letivo, em escolas da rede pública estadual e municipal de Minas Gerais.

As análises de Foucault (2011) dão azo para entendermos que organizar o tempo, o espaço, regulamentar as formas de pensamento, de ação e de discurso, a partir de um regulamento meticuloso é, resumidamente, uma forma modo de reger a vida dos indivíduos

\begin{tabular}{|l|l|l|l|l|}
\hline Qenista Dialectus & Ano 9 & n. 19 & Agosto-Dezembro 2020 & p. 256-276 \\
\hline
\end{tabular}


no interior de uma instituição escolar. Temos do mesmo modo uma função, um discurso a ser seguido, um lugar predeterminado para cada um, em suma, temos um "rosto bem definido" no que tange ao Dia “D” da escola mineira.

Nessa linha de pensamento, entendemos que o Dia "D" da Educação Mineira possui uma função governamental-pastoral, pois tem como finalidade a construção de um sujeito de consciência (voltado para os resultados, para os índices). Além disso, a figura do sujeito político (Governador de MG) por detrás da produção dos documentos atinentes ao Dia “D”, emerge tal qual a figura do "pastor", quer dizer, daquele que guia o rebanho. Entretanto, não é guiar o rebanho no sentido da "salvação", pelo contrário, trata-se de guiar no sentido dos resultados, dos melhores índices no IDEB, no PROALFA. Afinal, o pastor também é um ser político, visto que não guia seu rebanho tão somente por "bondade", mas o faz buscando sua própria "salvação", ora, o faz por um cargo político melhor.

Fundamentalmente, o escopo principal do dia "D", segundo o discurso político educacional da SEE/SRE, é mobilizar todos os professores e gestores, em um único dia, para pensar o presente planejando o futuro da educação em MG. "Em vez das aulas, professores e equipes pedagógicas se reúnem em suas escolas para discutirem os resultados em avaliações educacionais, as metodologias de ensino e para adequar o Plano de Intervenção Pedagógica (PIP)" (SEEMG, 2013, p. 1).

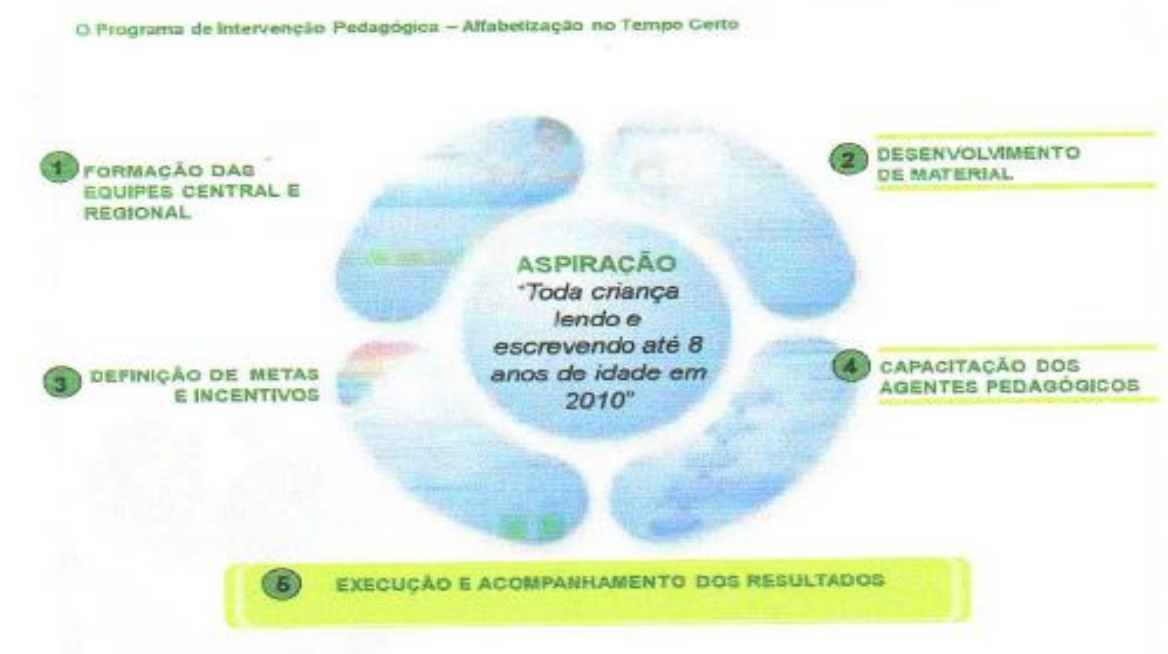

Figura 1 - Programa de Intervenção Pedagógica - Alfabetização em Tempo Certo Fonte: SEEMG (2010, p. 6).

\begin{tabular}{|l|l|l|l|l|}
\hline Q Povista Dialectus & Ano 9 & n. 19 & Agosto-Dezembro 2020 & p. 256-276 \\
\hline
\end{tabular}


A SEE/SRE defende que o Dia "D" é precípuo para garantir metodologias adequadas para verificar o desempenho do sistema. Respectivamente, abarca uma perspectiva contundente respeitante à realidade da Rede Pública de Ensino. Esse dia é essencial para identificar problemas a serem resolvidos e, igualmente, as demandas a serem atingidas. Com isso, contribuindo para o desenvolvimento de ações de melhoria na qualidade da educação (SEEMG, 2013).

Por uma perspectiva fora da visão política da SEE/SRE, se o "Dia D” (Operação Overlord) foi uma forma de derrubada de um soberano (Hitler), o Dia "D" em MG, é uma operação de jogada política que visou à constituição da figura de um sujeito político (Governador de MG) - "soberano" - a ser tomada como referência no cenário político nacional. Ora, esta manobra foi tão hábil, que a produção dos documentos (guias de elaboração do Dia "D”) ocorreu precisamente entre os anos de 2010 e 2011, ou seja, ano de transição de governo na esfera estadual e nacional.

Assim como a jogada política explicitada no parágrafo anterior, sob o slogan “tornar a educação de Minas Gerais referência em todo o Brasil" (SEEMG, 2010, p. 5), temos em voga, um discurso que propende para a formação de uma potência de Estado, de tal modo que, num aspecto, mantenha a Educação Mineira sob uma determinada ordem, disciplina, controle e, noutro aspecto, apresente um arquétipo de educação que possa ser assumido como modelo numa esfera nacional.

Todo este dia é orientado por um guia que subsidia todo o processo, indicando os passos necessários para organizar e desenvolver o planejamento das ações que acontecem nesse dia especial, medidas que orientam todas as demais ações dessa operação de "guerra" evidenciada. Esse guia é dividido em sete partes, as quais observam a apresentação, os papéis das instâncias regionais e a equipe da escola, além de orientar a implantação do Programa de Intervenção Pedagógica/Alfabetização no Tempo Certo (PIP/ATC), bem como acompanhá-lo, sendo esta uma tarefa conjunta entre SEE, SRE e Escolas, em que vale a máxima "toda escola pode e tem que fazer a diferença" (SEEMG, 2010, p. 22), máxima esta que é sumariamente o mote principal de campanha para as unidades escolares.

Diante disso, é precípuo ressaltar dois pontos. Primeiro, uma parte do guia, para relembrar alguns conceitos, o discurso pedagógico apresenta cinco compromissos para com a educação mineira ancorados no principal enunciado da política pública desse estado

\begin{tabular}{|l|l|l|l|l|}
\hline Govista Qialectus & Ano 9 & n. 19 & Agosto-Dezembro 2020 & p. 256-276 \\
\hline
\end{tabular}


federativo: "tornar a educação de Minas Gerais referência em todo o Brasil”" (SEEMG, 2010, p. 5), a grande meta e o alvo da guerra.

Esse discurso invoca nos sujeitos envolvidos o "desejo" de participação e pertencimento, afinal, “todos querem uma educação de qualidade". E uma educação nesses moldes requer uma política de resultados, porém, todo resultado engendra, por sua vez, competição numa esfera micro e macro: qual é o aluno com as melhores notas em uma escola $X$ ? Qual disciplina tem os melhores resultados numa escola X? Qual escola possui as melhores notas numa certa região ou no estado? Qual SRE possui o melhor índice junto ao IDEB? Qual estado possui o melhor IDEB no país?

Tais questões também se ligam a outros enunciados de participação e de pertencimento, sobretudo, no que corresponde aos "compromissos da Educação Mineira" (FIGURA 2). Orbitando ao redor do enunciado "Tornar a educação de MG referência em todo o Brasil", têm-se outros enunciados, igualmente "convocatórios" tais como os proferidos no "Dia D" em 1944: "comunidade participando" (Em que sentido? Atuando na melhoria dos "resultados"?); "todos os alunos progredindo juntos" (Em termos de "resultados"? Ou progredindo em ano/série?); "nenhum aluno a menos" (Nos "resultados"? No processo de alfabetização? Ou no âmbito da progressão de ano/série?). Na perspectiva bélica do "Dia D", tais enunciados poderiam ser substituídos por: "todo Estado-Nação juntos na guerra"; "todas as tropas aliadas e progredindo em direção a um único alvo"; "nenhum soldado a menos".

A figura, a seguir, ilustra tais suspeitas, questionamentos e problematizações sobre o Dia “D” da Educação Mineira:

\begin{tabular}{|l|l|l|l|l|}
\hline Qenista Dialectus & Ano 9 & n. 19 & Agosto-Dezembro 2020 & p. 256-276 \\
\hline
\end{tabular}




\section{Os compromissos da educaçāo mineira}

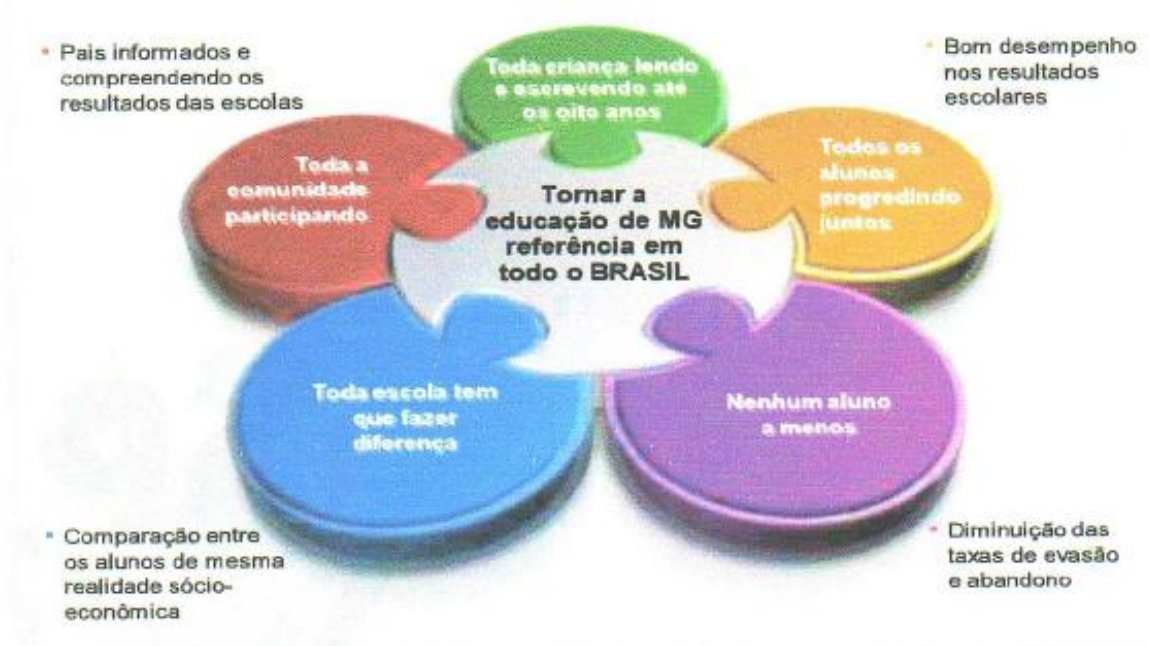

Figura 2 - Os compromissos da Educação Mineira.

Fonte: SEEMG (2010, p. 5).

De resto, na figura supra indicada, tem-se o enunciado "Toda escola tem que fazer diferença”. Neste último enunciado, nos chama a atenção o termo "tem que fazer". Ora, este é contrário ao termo "pode fazer". E, precisamente, o termo "pode fazer" está na capa do documento atinente ao Dia "D”. Nesse sentido, "tem que fazer" que nos remete a uma ordem direta: "faça a diferença ou será punido". Aqui é visível uma relação de ordem, de força, de imposição. O termo "pode", por outro lado, é mais maleável, flexível. "Pode fazer", indica uma possibilidade, isto é, se não o fizer, tudo bem, teremos outras oportunidades de fazê-lo, mas, ainda é preciso que se tente "fazer a diferença" (aqui temos uma relação de poder-saber). Nesse viés, as questões que nos incomodam são: "o que seria exatamente "fazer a diferença"”? Fazer a diferença é ter "resultados" melhores? É obter os melhores índices - IDEB?

Sumariamente, o Dia "D" supostamente serve como diagnóstico para se avaliar os sujeitos-alunos que precisam estar ao menos na "média" do IDEB, aqueles que precisam de “intervenção" (PIP) para atingirem bons "resultados". É imprescindível avaliar "quem merece" (princípio da meritocracia), para tanto, criam-se os indicadores de desempenho (IDEB, PROEB, SAEB, etc.), as políticas de resultados, os jogos estratégicos de poder-saber (Dia "D”), os discursos de equidade ("nenhum aluno a menos"), os discursos da "diferença" (“a escola tem que fazer diferença"). Supostamente (ou precisamente) o Dia "D” é, igualmente, um jogo estratégico, um jogo político no bojo da Educação Mineira.

\begin{tabular}{|l|l|l|l|l|}
\hline Govista Qialectus & Ano 9 & n. 19 & Agosto-Dezembro 2020 & p. 256-276 \\
\hline
\end{tabular}


Esse jogo político intenta a produção de verdades e, para consolidá-las, é necessário algum material empírico como prova, como meio de consolidação. É nesse sentido que a SEEMG faz uso das avaliações externas e internas e, por consequência, das estatísticas e indicadores correspondentes aos resultados dessas avaliações, como meio de alavancar um determinado discurso político, tal como o enunciado "Tornar a educação de MG referência em todo o Brasil”, ou ainda, meio de visibilizar uma determinada forma de governamento.

Por conseguinte, existe uma prática disciplinar (PIP), a qual é, essencialmente, um meio de elencar os "normais" (aqueles que obtêm índices satisfatórios nas avaliações), segregando-os dos considerados "anormais" (aqueles que apresentam defasagens em relação às capacidades e competências diante das avaliações). O PIP, nesse viés, é um arranjo inventariado para, precisamente, colocar em ação a "norma", separando e distinguindo os sujeitos-alunos em termos de resultados. Foucault $(2011,1997)$ depreende que qualquer que seja o processo avaliativo, este se coaduna a um conjunto de técnicas e punições que padronizam (normatizam), exercendo um poder que permite as classificações e punições (conforme a proposta do PIP).

A materialidade do discurso bélico do Dia "D” mostra o que a educação mineira tem de fazer para ser referência educacional no Brasil, por intermédio da produção de efeitos de sentido, como, por exemplo, "a escola precisar se organizar para se fazer sem saber ou mesmo sabendo":

\begin{abstract}
$\mathrm{O}$ conhecimento e a expertise formam o ponto nodal à volta do qual o mundo se apresenta pensável e são apresentadas as receitas necessárias para a sua domestificação. É por esta via que, em meu entender a governamentalidade pode constituir uma ferramenta aplicada à história da escola. Permitirá desencadear trabalhos de investigação que tomem como eixos analíticos a flexibilidade e a transferência permanentes, que saibam valorizar os quadros de ação e de associação que permitem que o governo, nas sociedades modernizadas, ocorra à distância e se organize em torno do princípio livre escolha do sujeito (Ramos do Ó, 2009, p. 114).
\end{abstract}

Para a realização do Dia "D" é necessário que tudo esteja em perfeita ordem e todo o conjunto de escolas do Estado de Minas Gerais esteja no mesmo dia (D), na mesma hora $(\mathrm{H})$ e no mesmo minuto (M), com uma agenda específica e com todos os armamentos apropriados para atuar nas trincheiras para atingir um inimigo em comum: o analfabetismo e/ou o fracasso presente nas estatísticas de alunos de baixo desempenho.

\begin{tabular}{|l|l|l|l|l|}
\hline Qenista Dialectus & Ano 9 & n. 19 & Agosto-Dezembro 2020 & p. 256-276 \\
\hline
\end{tabular}


Para tanto, utiliza professores, alunos e toda comunidade escolar para ser a linha de frente de uma batalha político-partidária que procura tornar Minas Gerais referência em educação para todo Brasil. Essa ação pode transformar (eleger) o principal comandante dessa operação de guerra (o governador do estado) em chefe de Estado da nação. Ou apresentar, discursivamente, Minas Gerais e suas escolas como um mercado competitivo, vivo e eficiente a fim de apresentá-lo como um estado capaz e central - regionalmente - no desenvolvimento de políticas educacionais. Portanto, agregador de forças estratégicas do jogo de poder-saber, visto por uma perspectiva em que fazer a prática da escola.

Seguindo essa ótica, o fazer escolar é apresentado como uma competição, o que justifica a afirmação do governo mineiro, em sua posição neoliberal, de que "toda a escola pode e tem que fazer diferença” (SEEMG, 2010, p. 22), diferença constituída em um pacto de metas realizado ano a ano, solenemente, com cada gestor escolar, propondo a excelência, a inovação, a melhoria do desempenho e de habilidades cada vez mais altas, para cada unidade escolar.

Nessa perspectiva, há indícios de meritocracia, de uma ordem gerida pela organização da produção, da tecnologia, da estrutura social, pelo viés da eficácia, do mérito, da medida, da utilidade, da produtividade.

O Dia "D” em Minas Gerais, em especial, se utiliza de estratégias bélicas para convocar todo um exército possível, "toda a comunidade participando" (SEEMG, 2010, p. 5), por meio de comandos que ativam certo sinal, um ficar em alerta para o combate; um constante alerta para as tropas e as guaritas estarem com seus combatentes preparados e em forma. "Todos devem estar a postos para a guerra!". Inclusive toda a comunidade deve estar atenta às estratégias do combate e dela tomarem partido.

Nessa guerra, o enunciado "toda escola tem que fazer a diferença" (SEEMG, 2010 , p. 5) tem a pretensão de reverter o quadro em que a escola se encontra. A escola como um batalhão precisa se organizar de tal forma, que todos os seus soldados, todos os seus cabos, todos os sargentos, capitães, coronéis e outros precisam combater com afinco para atingir e conquistar a meta e o alvo central. A escola precisa arquitetar suas trincheiras de combate, precisa realizar exercícios e treinamentos de comando. Precisa se privar de certas ações e munir de armamentos seu território, protegendo-se de todas as possibilidades de ataques terrestres e aéreos para não se deixar ser tomada pelo inimigo.

\begin{tabular}{|l|l|l|l|l|}
\hline Qenista Dialectus & Ano 9 & n. 19 & Agosto-Dezembro 2020 & p. 256-276 \\
\hline
\end{tabular}


Dessa maneira, todos são importantes para a batalha ou a campanha. "Nenhum aluno a menos" (SEEMG, 2010, p. 5), não se pode pensar em baixas, ninguém pode ser abatido, não se deve imaginar mortos (desistências) e perdas (evasões) pelo caminho. Todo o batalhão precisa vencer (voltar à base) e receber congratulações e medalhas de honra ao mérito pelos esforços dispendidos.

Quando finalmente a bandeira branca estiver balançando no alto do mastro, quando alcançar que "toda criança (estiver) lendo e escrevendo até os oito anos (de idade)" (SEEMG, 2010, p. 6), a Educação de Minas Gerais, mesmo que provisoriamente, será referência em todo o Brasil. Ora, finalmente, ganhou-se a guerra.

Pode-se, então, expandir para toda a nação a experiência militar-escolar mineira.

\begin{abstract}
A criação das políticas nacionais é, inevitavelmente, um processo de "bricolagem"; um constante processo de empréstimos e cópia de fragmentos e parte de ideias de outros contextos, de uso e melhoria das abordagens locais já tentadas e testadas, de teorias canibalizadoras, de instigação, de adoção de tendências e modas e, por vezes, de investimento em tudo aquilo que possa a vir funcionar. A maior parte das políticas frágeis, produto de acordos, algo que pode ou não funcionar; elas são retrabalhadas, aperfeiçoadas, ensaiadas, crivadas de nuances e moduladas através de complexos processos de influência, produção e disseminação de textos e, em última análise, recriadas nos contextos da prática (Ball, 2001, p. 102).
\end{abstract}

Entrementes, os fuzis, as bombas químicas, as estratégias, os jogos estratégicos não desaparecerão, devem permanecer, uma vez que quando um exército ou uma nação conquista o seu alvo, outras estratégias bélicas, fortemente fundamentadas, emergem, produzindo outros sentidos para que nada se abata sobre o poder-saber do governamento e da governamentalidade. Afinal, outras estratégias militares-curriculares emergirão dessa teia de relações de poder-saber.

\title{
CONSIDERAÇÕES...
}

No presente artigo, a partir de uma análise crítica sobre o Guia para organização do Dia "D” ("Guia de orientação para a reorganização e implementação do Plano de Intervenção Pedagógica - 2010/2011”) e, em partes, acerca dos discursos referentes ao Dia “D” presentes no documento: “Guia de revisão e reorganização do Plano de Intervenção Pedagógica - 2013" (como meio complementar), nós constatamos que o Dia "D” da Educação Mineira possui uma função governamental-pastoral, já que tem como objetivo a construção de

\begin{tabular}{|c|c|c|c|c|}
\hline Rovista Dialectus & Ano 9 & n. 19 & Agosto - Dezembro 2020 & p. $256-276$ \\
\hline
\end{tabular}


um sujeito de consciência, que está voltado para os resultados das avaliações externas e para os índices do PROALFA, IDEB, SIMAVE, PROEB, etc.

Nesse sentido, concebemos que o Dia "D” da Educação Mineira foi uma operação de jogada política que visou à constituição da figura de um sujeito político (Governador de MG) - "soberano" - a ser tomada como referência no cenário político nacional.

Depreendemos ainda que para ser atingido este objetivo, era necessário um enunciado que causasse impacto, que mobilizasse sujeitos-professores, sujeitos-alunos, sujeitos-diretores, que despertasse um sentimento de pertencimento a todos os envolvidos. Portanto, escolheu-se o nome de Dia "D".

Portanto, o enunciado Dia "D", tal qual o Dia D (Segunda Guerra Mundial), ilustrou um momento marcado por um cronograma rígido e preestabelecido, em que tinha também um processo de mobilização dos professores (os mesmos são passiveis de punição caso se ausentem), existia todo um roteiro a ser seguido, com relatórios pós-Dia "D", relatórios de intervenção pedagógica (PIP), metas a serem alcançadas, e, é claro, um guia norteador (documento analisado na presente pesquisa). Todo este plano, esta mobilização, a ser aplicada em um único dia letivo, em escolas da rede pública estadual e municipal.

Enfim, findamos as nossas problematizações, críticas e suspeitas, aludindo que os fuzis, as bombas químicas, as estratégias militares, os jogos estratégicos não desaparecerão, devem permanecer, uma vez que quando um exército e/ou uma nação conquista o seu alvo, outras estratégias bélicas, fortemente fundamentadas, emergem, produzindo outros sentidos, outras relações de poder-saber, outras práticas discursivas, para que nada se abata sobre o poder-saber do governamento e da governamentalidade. Portanto, outras estratégias militarescurriculares emergirão dessa teia de relações de poder-saber, a qual evidencia o Dia "D" da Educação Mineira.

\section{REFERÊNCIAS}

BALL, S. J. Diretrizes políticas globais e relações políticas locais em educação. Currículo sem fronteiras, v. 1, n. 2, 2001, p. 99-116.

BRASIL. Lei de Diretrizes e Bases da Educação Nacional - LDB. Lei nº 9394/1996. 5. ed. Brasília: Centro de Documentação e Informação - Edições Câmara, 2010.

DAVIES, N. Europa na Guerra, uma vitória nada simples. São Paulo: Record, 2009.

\begin{tabular}{|l|l|l|l|l|}
\hline Q Pevista Dialectus & Ano 9 & n. 19 & Agosto-Dezembro 2020 & p. 256-276 \\
\hline
\end{tabular}


FOUCAULT, M. Qu'est-ce que la critique? Critique et Aufklärung. Bulletin de la Société française de philosophie, v. 82, n. 2, avr./juin. 1990, p. 35-63 (Conferência proferida em 27 de maio de 1978).

Zahar, 1997.

. Resumo dos Cursos do Collège de France (1970-1982). Rio de Janeiro: Jorge . Segurança, território, população. São Paulo: Martins Fontes, 2008.

Achiamé, 2010.

Do governo dos vivos: Curso no Collège de France, 1979-1980. Rio de Janeiro:

. Vigiar e punir: nascimento da prisão. 39. ed. Petrópolis: Vozes, 2011.

FIMYAR, O. Governamentalidade como ferramenta conceitual na pesquisa de políticas educacionais. Educação e Realidade, v. 34, n. 2, 2009, p 35-56.

GADELHA, S. Biopolítica, governamentalidade e educação: introdução e conexões, a partir de Michel Foucault. Belo Horizonte: Autêntica, 2009a.

Governamentalidade neoliberal, Teoria do Capital Humano e Empreendedorismo.

Educacao e Realidade. v. 34, n. 2, mai./ago. 2009b, p. 171-186.

GALLO, S. Infância e Resistência: resistir a quê? Leitura: Teoria \& Prática, Campinas, v. 31, n. 61, nov. 2013, p.199-211.

MASCIA, M. A. A. Investigações na pós-modernidade: uma análise das relações de podersaber do discurso político educacional de língua estrangeira. Campinas: Mercado de Letras, 2002.

RAMOS do Ó, J. A. Governamentalidade e a história da escola moderna: outras conexões investigativas. Educação e Realidade, v. 34, n. 2, 2009, p. 97-117.

O governo do aluno na modernidade. Revista Segmento. Dossiê: Foucault pensa a educação. 2007, p. 36-45.

SEEMG. Guia de Orientação e Reorganização do Plano de Intervenção Pedagógica. Belo Horizonte: SEE, 2010-2011.

SEEMG. Guia de Revisão e Reorganização do Plano de Intervenção Pedagógica. Belo Horizonte: SEE, 2013.

SEEMG. Secretaria de Estado de Educação de Minas Gerais. Sistema Mineiro de Avaliação da Educação Pública (SIMAVE), 2013.

Disponível em: https://www.educacao.mg.gov.br/ajuda/page/15115-simave. Acesso em: 12/01/2016.

\begin{tabular}{|l|l|l|l|l|}
\hline Q Povista Qialectus & Ano 9 & n. 19 & Agosto-Dezembro 2020 & p. $256-276$ \\
\hline
\end{tabular}


SECRETARIA DE ESTADO DE EDUCAÇÃO DE MINAS GERAIS. Conteúdo Básico Comum (CBC): Língua Portuguesa (Educação Básica - Ensino Fundamental e Médio). Belo Horizonte: SEE, 2007.

\begin{tabular}{|c|c|c|c|c|}
\hline Revista Dialectus & Ano 9 & n. 19 & Agosto - Dezembro 2020 & p. $256-276$ \\
\hline
\end{tabular}

